\title{
Controle Interno: Responsabilidades e Execução em Indústrias Paraibanas
}

Márcia Cristiane da Silva Vasconcelos

marciacristiane2005@gmail.com Universidade Federal da Paraíba (UFPB), João Pessoa, Paraíba, Brasil.

\section{Vera Lucia Cruz}

Universidade Potiguar (UnP). Natal, Rio Grande do Norte, Brasil.

\section{Ramon Rodrigues dos Santos} ramonrdgs@gmail.com

Universidade Federal de Pernambuco (UFPE), Recife, Pernambuco, Brasil.

\section{Rodrigo José Guerra Leone} Rodrigo.leone@gestorfp.com.br Universidade Potiguar (UnP). Natal, Rio Grande do Norte, Brasil.

\author{
RESUMO
}

O Controle Interno contribui com informações fidedignas para a tomada de decisão nas organizações. Portanto, esta pesquisa teve como objetivo evidenciar qual a unidade responsável pelo Controle Interno nas Indústrias dos municípios de Santa Rita e Bayeux, na Paraíba. Para isso, realizou-se uma pesquisa de campo, através da aplicação de um questionário chegando-se ao quantitativo de 68 respondentes. De acordo com os dados obtidos, foi evidenciado que a responsabilidade do Controle Interno nos municípios analisados é, em geral, da auditoria interna e da gerência. Quanto à independência na execução das atividades, a maioria dos respondentes afirmou que a controladoria tem independência. Já em relação às atividades desenvolvidas pelas unidades coletadas na pesquisa foram apontados os controles internos, controle e acompanhamento Contábil, além da auditoria de processos, planejamento estratégico e custos. Com base nos resultados, sugere-se que as empresas avaliem os resultados dos trabalhos desses profissionais, para verificar se a sua execução atende as necessidades da empresa, tendo em vista que a preparação acadêmica para execução dessas atividades é do Controller ou do Auditor Interno.
\end{abstract}

PALAVRAS-CHAVE: Auditoria Interna. Controladoria. Controle Interno. 


\section{INTRODUÇÃO}

As empresas no desenvolvimento de suas atividades estão em constante busca por controle, para conseguir fazer com que tudo esteja dentro dos padrões pretendidos por elas. Para enfrentar tais circunstâncias, as empresas precisam utilizar alguns conceitos e técnicas que possibilitem controle de seu desempenho (MOSIMANN; FISCH, 2009).

De acordo com o Committee of Sponsoring Organizations of the Treadway Commission (COSO, 2004), "controles internos" são processos operados pelo Conselho de Administração, Administração e outras pessoas, ora desenhado de forma a fornecer segurança razoável. Com base na definição do COSO, evidenciase que a área de controles internos pode ajudar no desenvolvimento das empresas com informações de todo o seu processo. Entretanto, existem alguns posicionamentos com relação a quem caberia essa responsabilidade do controle interno, se da auditoria interna ou da controladoria.

$\mathrm{Na}$ Controladoria, o responsável é denominado de gerente de controladoria ou Controller. Consoante Garcia (2008), o controller tem o papel de auxiliar os gestores das empresas na implementação de melhores práticas de controle para permitir informações com integridade, fornecendo informações para a contabilidade. Logo, entende-se que o Controller participa de todo o processo de controle interno, fornecendo informações confiáveis para a contabilidade, assim como também para a gestão das organizações. Em complemento, a auditoria interna compreende a avaliação e adequação de controles internos, interpretando os riscos, seus impactos e a probabilidade da sua ocorrência, de modo a propiciar controles eficazes que auxiliam os administradores (VASCONCELOS et al., 2017).

Nestas perspectivas, há uma discordância entre os autores, analisada no transcorrer deste estudo, buscando contribuir para o entendimento da responsabilidade das atividades de controle interno nas empresas (se da controladoria ou da auditoria interna) visto que as mesmas costumam desempenhar papéis semelhantes.

Considerando que essas duas unidades administrativas de controle interno, em geral, estão no mesmo contexto, exercendo as mesmas funções, e sem chegar a um consenso, o presente artigo tem como questão de pesquisa: Qual é a unidade administrativa responsável pelas atividades de controle interno nas indústrias dos municípios de Santa Rita e Bayeux, na Paraíba?

A escolha da amostra tomou por base as informações colhidas do Instituto Brasileiro de Geografia e Estatística que apontou, há época, estes municípios como líderes no segmento Industrial na Paraíba e por serem as primeiras cidades paraibanas a receberem instalações fabris. Ademais, é importante ressaltar que o município de Bayeux fazia parte da cidade de Santa Rita, como distrito, porém, com a Lei Estadual n.o 2.148, de 28 de julho de 1959, Elevado à categoria de município (IBGE, 2018).

Dessa forma, esta pesquisa visa contribuir para a compreensão da necessidade do controle interno nas indústrias dos municípios de Santa Rita e Bayeux, apresentando qual a unidade responsável por sua execução, assim como, colaborar no aprofundamento de estudos sobre o tema, buscando subsidiar 
outras investigações e projetos, além de contribuir com os usuários da informação, gestores, professores, entre outros.

\section{REVISÃO DA LITERATURA}

\section{CONTROLE INTERNO, AUDITORIA E CONTROLADORIA}

O Comitê de Procedimentos de Auditoria do American Institute of Certified Public Accountants ou, em Português, Instituto Americano de Contadores Públicos Certificados define "controle interno" como o plano de organização e conjunto coordenado dos métodos e medidas, adotados pela empresa, para proteger seu patrimônio, verificar a exatidão e a fidedignidade de seus dados contábeis (AICPA, 2019). Em complemento, Attie (2011) destaca que o controle interno tem quatro objetivos básicos: (a) a salvaguarda dos interesses da empresa; (b) a precisão e a confiabilidade dos informes e relatórios contábeis, financeiros e operacionais; (c) o estímulo à eficiência operacional; e (d) aderência às políticas existentes.

Os objetivos primordiais dos controles internos são fornecer à contabilidade dados corretos e conferir a exatidão da escrituração; evitar alcances, desperdícios, erros e, se ocorridos, identificá-los (FRANCO, 2009). Neste aspecto, os objetivos mencionados por Attie (2011) e Franco (2009) podem ser direcionados para aos sistemas contábil e financeiro, e instituídos em diversas áreas da empresa, como a administração, produção, comercial, manutenção e expedição.

Já em relação à auditoria, compreende-se que esta busca evidências de informações de caráter interno e seguem às normas de auditoria, visto que a Auditoria Interna levanta dados confiáveis para avaliação dos controles internos e é exercida por um profissional da empresa que está ao lado da presidência dando suporte na tomada de decisão (SANTOS, TRÊS, 2012).

Para Attie (2011), as análises de auditoria buscam a verificação documental, os livros e registros com características controladoras, como também a obtenção de evidências de informações de caráter interno ou externo que tenham relação com o patrimônio, bem como a precisão dos registros e as demonstrações decorrentes. A auditoria Interna é exercida por um funcionário da própria empresa, porém, mesmo tendo vínculo com a empresa em caráter permanente, é um profissional independente submetido às normas de auditoria e controladoria (SANTOS; TRES, 2012).

Já a controladoria era historicamente ligada à contabilidade, porém, ao longo dos anos, perdeu suas características unilaterais, tornando-se multidisciplinar. Com isso, deixou de ser essencialmente contábil e passou a envolver conhecimentos relacionados a outras ciências, como administração, economia, estatística, psicologia, que, atualmente, são empregadas em conjunto com a contabilidade (LUNKES; SCHONORRENBERGER, 2009).

De acordo com Garcia (2010), a controladoria alimenta todo o processo de gestão da organização, subsidiando os gestores com informações seguras e consistentes com vistas à eficaz tomada de decisões e essas informações tem como base o sistema de controles internos. Estudos como os de Lunkes e Schonorrenberger 
(2009), Mosimann e Fisch (2009), Garcia (2010), Oliveira, Perez Júnior e Silva (2013) e Perez e Silva (2013) tem a controladoria como responsável pelo controle interno nas organizações.

Por outro lado, Attie (2011), Santos e Três (2012) e Martins e Morais (2013), defendem ser da auditoria interna a responsabilidade do controle interno nas organizações. Neste contexto, não há um consenso por parte dos autores em desempenhar papéis semelhantes.

\section{ESTUDOS CORRELATOS}

É possível identificar na literatura trabalhos que explorem os aspectos da presente pesquisa em temas adjacentes, com a utilização de outras unidades de caso ou regiões e em períodos diferentes. Neste contexto, o presente tópico apresenta os estudos mais recentes.

Santos e Três (2012) abordaram o entendimento dos gestores públicos dos municípios do Corede Produção/RS, em relação ao controle interno, à auditoria interna e à controladoria como instrumentos e técnicas que podem ser utilizadas nos municípios, no intuito de auxiliar a administração na busca pela eficácia e eficiência no serviço público. $O$ objetivo geral consistiu em avaliar o entendimento desses gestores acerca da atuação da controladoria, auditoria interna e controle interno no âmbito local.

Os dados foram coletados através de um questionário formatado em dois blocos com perguntas fechadas, moldado pela escala de Likert e enviado por e-mail aos prefeitos ou vice-prefeitos no período de agosto a outubro de 2011. Como respostas, foram desenvolvidos 19 questionários, constatando-se que somente $15 \%$ dos gestores pesquisados possuem clareza sobre as atribuições e finalidades da controladoria, auditoria interna e do controle interno.

Martins (2014) abordou o entendimento dos gestores municipais da microrregião de Xanxerê, em Santa Catarina, quanto à importância da auditoria interna, controladoria e controle interno, com o intuito de gerar informações relevantes à administração pública na melhoria do serviço público. O objetivo geral foi o de avaliar a compreensão dos gestores sobre a atuação da auditoria interna, controladoria e controle interno nos municípios da microrregião. Foi enviado um questionário para 17 municípios, tendo-se o retorno de 12 respostas, sendo possível constatar que, em média, $41,67 \%$ dos respondentes possuem o entendimento correto das atividades da auditoria interna, controladoria e controle interno. Contudo, nota-se a falta de clareza sobre tais atribuições por parte do entendimento da maioria dos gestores.

Kataoka et al. (2018) investigaram a atribuição das atividades de controle interno desenvolvidas nas empresas de grande porte do estado de Pernambuco, observando que, tanto a Controladoria, quanto a auditoria interna atuam como participantes das mudanças processadas pelas empresas avaliando controles e sugerindo ações e ajustes necessários. Observou-se, dentre as empresas pesquisadas, que a Controladoria estava hierarquicamente subordinada a alguma diretoria e que a auditoria estava subordinada à presidência e a alguma diretoria. De forma geral, isto conclui que as atividades de controle interno nas empresas de grande porte do estado de Pernambuco são executadas pela Controladoria, 
porém, o controle interno é exercido tanto pela Controladoria, quanto pela Auditoria, não existindo um consenso.

De acordo com os estudos expostos, tanto a Auditoria Interna, quanto a Controladoria contribuem para o controle interno no processo de gestão, planejando e principalmente fornecendo informações fidedignas para a tomada de decisão, porém, ainda assim, não há a um consenso sobre a responsabilidade do mesmo, percebendo-se também a falta de clareza sobre as atribuições da Auditoria Interna e da Controladoria por parte da maioria dos gestores.

\section{METODOLOGIA}

Considera-se este estudo como descritivo, pois visa evidenciar qual unidade administrativa é responsável pelo controle interno nas indústrias de Santa Rita e Bayeux. Os procedimentos começaram por revisões bibliográficas da literatura pertinente, para que, a posteriori, fosse realizada uma pesquisa de campo. Consoante Gil (2008), pesquisas deste tipo procuram o aprofundamento de uma realidade específica. Em complemento, estas são basicamente realizadas por meio da observação direta das atividades do grupo estudado e de entrevistas com informantes para captar as explicações e interpretações que ocorrem naquela realidade. Neste aspecto, será utilizado um questionário para evidenciar qual a unidade administrativa é responsável pelo controle interno nas empresas.

Este estudo foi baseado no trabalho de Kataoka et al. (2018) que concluiu que as atividades de controles internos são desenvolvidas tanto pela controladoria quanto pela auditoria interna, sem chegar a um consenso, abrindo assim, precedentes para novas pesquisas.

Com o intuito de alcançar o propósito deste artigo, foi levantado o quantitativo das indústrias dos municípios de Santa Rita e Bayeux, na Paraíba, que, de acordo com a Federação das Indústrias do Estado da Paraíba (FIEP/PB), são 226 indústrias, das quais 130 estão no município de Santa Rita e 96, em Bayeux. Da população de 226 indústrias, foi extraída uma amostra de 68 indústrias, sendo 39 na cidade de Santa Rita e 29 no município de Bayeux, correspondendo a 30\% e $30,2 \%$ respectivamente.

Com a finalidade de identificar o porte das Indústrias pesquisadas, recorre-se ao Serviço Brasileiro de Apoio às Micro e Pequenas Empresas (SEBRAE, 2016), que classifica as empresa segundo o número de empregados que a empresa possui. Esta classificação é ilustrada no Quadro 1.

Quadro 1 - Classificação do Porte das Indústrias

\begin{tabular}{|c|c|}
\hline Quantidade de Empregados & Classificação \\
\hline Até 19 empregados & Micro Indústrias \\
\hline De 20 a 99 empregados & Pequeno Porte \\
\hline De 100 a 499 empregados & Médio Porte \\
\hline Acima de 500 empregados & Grande Porte \\
\hline
\end{tabular}

Fonte: SEBRAE (2016)

Para a coleta de dados, adaptou-se o questionário do artigo-base para este estudo, o qual foi inserido uma coluna de outras unidades, levando em 
consideração que a pesquisa achou uma discordância quanto à responsabilidade do controle interno entre as unidades de auditoria interna e controladoria. O questionário foi composto por oito perguntas divididas em objetivas e subjetivas, direcionando-as aos responsáveis pelo setor de controladoria de cada indústria respondente, aplicando estes através de e-mails, telefone ou presencialmente.

Além disso, o questionário foi dividido em cinco partes, cujas partes indicavam informações sobre (a) quantidade de funcionários; (b) existência e responsabilidade do controle interno; (c) independência na execução das atividades; (d) execução de atividades; e (e) principais atividades desenvolvidas.

$\mathrm{Na}$ primeira parte, buscou-se a quantidade de funcionários das indústrias, visando identificar o porte da empresa pesquisada; a segunda, visava identificar se as indústrias possuíam algum tipo de controle e quem era o responsável; a terceira parte tinha como objetivo saber se existia independência na função; a quarta, buscava saber sobre a execução do trabalho; e a quinta, quais as principais atividades desenvolvidas pela auditoria interna ou pela controladoria.

Por fim, os dados obtidos foram tabulados no Microsoft Excel, com o intuito de ajudar na compreensã, e identificar se os resultados foram de encontro aos objetivos fixados na presente pesquisa.

\section{RESULTADOS E DISCUSSÃO}

Como supracitado na metodologia, foram analisadas 68 indústrias, ora estavam incluídas e atendendo aos requisitos deste estudo. Na Tabela 1 buscou-se identificar qual a distribuição das indústrias coletadas em relação ao seu porte, conforme o SEBRAE (2016).

Tabela 1 - Quantidade de Empregados $x$ Municípios

\begin{tabular}{ccccc}
$\begin{array}{c}\text { Quantidades de } \\
\text { Empregados }\end{array}$ & $\begin{array}{c}\text { Indústrias de } \\
\text { Santa Rita }\end{array}$ & $\%$ & $\begin{array}{c}\text { Indústrias de } \\
\text { Bayeux }\end{array}$ & $\%$ \\
Até 19 & 20 & 51,3 & 15 & 51,8 \\
De 20 a 99 & 10 & 25,7 & 9 & 31,0 \\
De 100 a 499 & 4 & 10,2 & 2 & 6,9 \\
Acima de 500 & 5 & 12,8 & 3 & 10,3 \\
Total & 39 & 100,0 & 29 & 100,0 \\
\hline
\end{tabular}

Fonte: Dados da Pesquisa (2018)

Os resultados destacaram que, em relação aos dados coletados, o município de Santa Rita possui $51,3 \%$ de Micro Indústrias, $25,7 \%$ de Indústrias de Pequeno Porte, $10,2 \%$ de Indústrias de Médio Porte e 12,8\% de Indústrias de Grande Porte. Em seguida, verificou-se a existência do controle interno nas indústrias estudadas, conforme os resultados na Tabela 2.

Tabela 2 - Existência do Controle Interno $x$ Municípios

\begin{tabular}{ccccc}
$\begin{array}{c}\text { Quantidades de } \\
\text { Empregados }\end{array}$ & $\begin{array}{c}\text { Indústrias de } \\
\text { Santa Rita }\end{array}$ & $\%$ & $\begin{array}{c}\text { Indústrias de } \\
\text { Bayeux }\end{array}$ & $\%$ \\
Sim & 35 & 89,7 & 25 & 86,2 \\
Não & 4 & 10,3 & 4 & 13,8 \\
Total & 39 & 100,0 & 29 & 100,0 \\
\hline
\end{tabular}


Fonte: Dados da Pesquisa (2018)

A pesquisa revelou, conforme exposto na Tabela 2 , que, em relação à existência do Controle Interno nas indústrias do município de Santa Rita, 89,7\% possuem controle interno; já no município de Bayeux, $86,2 \%$ possuem e nos dois municípios, em geral, $88,2 \%$ da amostra total, afirmaram possuir algum tipo de controle.

Em sequência, a Tabela 3 apresenta resultados que buscaram destacar sobre qual responsável estaria a responsabilidade pelo controle interno da empresa.

Tabela 3 - Responsabilidade do Controle Interno

\begin{tabular}{ccc} 
Responsáveis & Frequência & $\%$ \\
Auditor Interno & 14 & 20,6 \\
Gerente & 14 & 20,6 \\
Controller & 10 & 14,7 \\
Não tem Responsável & 8 & 11,7 \\
Proprietário & 6 & 8,8 \\
Diretor de Produção & 6 & 8,8 \\
Diretor Administrativo & 5 & 7,5 \\
Supervisor & 3 & 4,4 \\
Contador & 2 & 2,9 \\
Total & 68 & 100,0 \\
\hline
\end{tabular}

Fonte: Dados da Pesquisa (2018)

Os resultados da Tabela 3 demonstram que 20,6\% afirmam que a responsabilidade do Controle Interno é do Auditor Interno, porém, com a mesma porcentagem outros respondentes alegam ser dos Gerentes essa responsabilidade. Em sequência, $14,7 \%$ atribuíram ao Controller; $4,4 \%$ ao Supervisor; 8,8\% ao sócio-proprietário da indústria; 8,8\% ao Diretor de Produção; $7,5 \%$ ao Diretor Administrativo; $2,9 \%$ ao Contador; e $11,7 \%$ não identificaram responsáveis pelo Controle Interno.

Em complemento, foi observado que mesmo constando na literatura que a responsabilidade do Controle Interno é do Auditor Interno (ATTIE, 2011; SANTOS; TRÊS , 2012; MARTINS; MORAIS, 2013) e/ou do Controller da entidade (LUNKES; SCHONORRENBERGER, 2009; MOSIMANN; FISCH, 2009; GARCIA, 2010; OLIVEIRA; PEREZ JÚNIOR; SILVA, 2013; PEREZ; SILVA, 2013), na prática em municípios pequenos, a realidade se apresenta diferente, sem os profissionais adequados para fazer o controle, ora utilizando outros profissionais para realizar esse papel.

Para a próxima parte, os respondentes foram abordados sobre a independência na execução das atividades. Cabe ressaltar que, na amostra coletada, 8 (oito) indústrias não fazem nenhum tipo de controle. Ademais, 5 (cinco) empresas possuem ambas as unidades administrativas (auditoria interna e controladoria), segundo os respondentes, executando as atividades. Neste aspecto, os valores da Tabela 4 divergem das amostras expostas nas Tabelas 1, 2 e 3.

Com isso, dos dados que estão expostos na Tabela 4, foram retiradas as respostas das que não executam, acrescentando-se as 5 (cinco) empresas que possuem as 
unidades de controladoria e auditoria, chegando-se assim, aos 65 respondentes que executam as atividades de controle interno, conforme destacado na Tabela 4.

Tabela 4 - Independência na Execução das Atividades

\begin{tabular}{ccccc} 
Unidades & Sim & $\%$ & Não & $\%$ \\
Administrativas & 7 & 33,2 & 4 & 9 \\
Controladoria & 6 & 28,6 & 12 & 27,3 \\
Auditoria Interna & 28,6 & 0 & 0 \\
Proprietário & 6 & 4,8 & 5 & 11,4 \\
Direção de & 1 & 4,8 & 1 & 2,3 \\
Produção & 1 & 0 & 3 & 6,8 \\
Contabilidade & 0 & 0 & 14 & 31,8 \\
Supervisão & 0 & 0 & 5 & 11,4 \\
Gerência & 0 & 100 & 44 & 100 \\
Direção & 21 & & & \\
Administrativa & Total & & & \\
\hline
\end{tabular}

Fonte: Dados da Pesquisa (2018)

Consoante a Tabela 4, em relação à independência na execução das atividades, $33,2 \%$ dos respondentes afirmaram que a controladoria possui independência; já a auditoria interna apresentou $28,6 \%$. Em seguida, buscou-se identificar por qual unidade administrativa são executadas as atividades de controle, verificação com as leis e procedimentos e o acompanhamento e utilização dos recursos. Os resultados destacaram que, em relação à conformidade dos controles internos na organização, estas são executadas por outras unidades chegando a $60 \%$ da amostra total.

A posteriori, a pesquisa buscou identificar quais as principais atividades desenvolvidas pelo controle interno das respectivas indústrias, destacando que algumas atividades podem ser desenvolvidas tanto pela Auditoria Interna quanto pela Controladoria, ou até mesmo por outras unidades, conforme pode ser destacado na Tabela 5.

Tabela 5 - Principais Atividades Desenvolvidas (Continua)

\begin{tabular}{|c|c|c|c|c|c|c|c|c|c|c|}
\hline \multirow[t]{2}{*}{ Atividades } & \multicolumn{2}{|c|}{ Auditoria } & \multicolumn{2}{|c|}{$\begin{array}{l}\text { Controla- } \\
\text { doria }\end{array}$} & \multicolumn{2}{|c|}{ Ambos } & \multicolumn{2}{|c|}{ Outra } & \multicolumn{2}{|c|}{ Total } \\
\hline & Freq & $\%$ & Freq & $\%$ & Freq & $\%$ & Freq & $\%$ & Freq & $\%$ \\
\hline Controles Internos & 13 & 21,7 & 6 & 10 & 5 & 8,3 & 36 & 60 & 60 & 100 \\
\hline $\begin{array}{c}\text { Controle e } \\
\text { Acompanhamento } \\
\text { Contábil }\end{array}$ & 0 & 0 & 2 & 50 & 0 & 0 & 2 & 50 & 4 & 100 \\
\hline $\begin{array}{l}\text { Auditoria de } \\
\text { Processos }\end{array}$ & 13 & 27 & 0 & 0 & 0 & 0 & 36 & 73 & 49 & 100 \\
\hline $\begin{array}{l}\text { Planejamento } \\
\text { Estratégico }\end{array}$ & 0 & 0 & 5 & 100 & 0 & 0 & 0 & 0 & 5 & 100 \\
\hline Custos & 3 & 33,4 & 4 & 44,4 & 0 & 0 & 2 & 22 & 9 & 100 \\
\hline $\begin{array}{c}\text { Análise e Formação } \\
\text { de Preços }\end{array}$ & 5 & 62,5 & 3 & 37,5 & 0 & 0 & 0 & 0 & 8 & 100 \\
\hline $\begin{array}{l}\text { Revisão e Controle } \\
\text { de Processos }\end{array}$ & 13 & 27 & 0 & 0 & 0 & 0 & 36 & 73 & 49 & 100 \\
\hline
\end{tabular}


Tabela 5 - Principais Atividades Desenvolvidas (Conclusão)

\begin{tabular}{|c|c|c|c|c|c|c|c|c|c|c|}
\hline \multirow[t]{2}{*}{ Atividades } & \multicolumn{2}{|c|}{ Auditoria } & \multicolumn{2}{|c|}{$\begin{array}{c}\text { Controla- } \\
\text { doria }\end{array}$} & \multicolumn{2}{|c|}{ Ambos } & \multicolumn{2}{|c|}{ Outra } & \multicolumn{2}{|c|}{ Total } \\
\hline & Freq & $\%$ & Freq & $\%$ & Freq & $\%$ & Freq & $\%$ & Freq & $\%$ \\
\hline Orçamento & 13 & 21,7 & 6 & 10 & 5 & 8,3 & 36 & 60 & 60 & 100 \\
\hline $\begin{array}{l}\text { Relatórios } \\
\text { Gerenciais }\end{array}$ & 13 & 21,7 & 6 & 10 & 5 & 8,3 & 36 & 60 & 60 & 100 \\
\hline Controle Fiscal & 0 & 0 & 5 & 20 & 0 & 0 & 20 & 80 & 25 & 100 \\
\hline $\begin{array}{l}\text { Acompanhamento } \\
\text { de Resultados }\end{array}$ & 0 & 0 & 5 & 100 & 0 & 0 & 0 & 0 & 5 & 100 \\
\hline Contabilidade & 0 & 0 & 2 & 50 & 0 & 0 & 2 & 50 & 2 & 100 \\
\hline Tesouraria & 0 & 0 & 1 & 100 & 0 & 0 & 0 & 0 & 1 & 100 \\
\hline $\begin{array}{l}\text { Avaliação de } \\
\text { Desempenho }\end{array}$ & 0 & 0 & 5 & 100 & 0 & 0 & 0 & 0 & 5 & 100 \\
\hline Inventário Mensal & 0 & 0 & 2 & 50 & 0 & 0 & 2 & 50 & 2 & 100 \\
\hline $\begin{array}{l}\text { Verificação de } \\
\text { Normas e Proc. }\end{array}$ & 9 & 16,5 & 5 & 9 & 5 & 9 & 36 & 66 & 55 & 100 \\
\hline $\begin{array}{c}\text { Suporte a Auditoria } \\
\text { Externa }\end{array}$ & 10 & 100 & 0 & 0 & 0 & 0 & 0 & 0 & 10 & 100 \\
\hline Teste de Receitas & 10 & 100 & 0 & 0 & 0 & 0 & 0 & 0 & 10 & 100 \\
\hline $\begin{array}{c}\text { Teste de Inventário } \\
\text { do Ativo } \\
\text { Imobilizado }\end{array}$ & 10 & 100 & 0 & 0 & 0 & 0 & 0 & 0 & 10 & 100 \\
\hline $\begin{array}{c}\text { Teste de Inventário } \\
\text { do Almoxarifado }\end{array}$ & 10 & 100 & 0 & 0 & 0 & 0 & 0 & 0 & 10 & 100 \\
\hline $\begin{array}{c}\text { Teste de Certidões } \\
\text { Negativas }\end{array}$ & 10 & 100 & 0 & 0 & 0 & 0 & 0 & 0 & 10 & 100 \\
\hline $\begin{array}{l}\text { Teste no Pessoal } \\
\text { por centro }\end{array}$ & 10 & 100 & 0 & 0 & 0 & 0 & 0 & 0 & 10 & 100 \\
\hline $\begin{array}{c}\text { Teste no Inventário } \\
\text { de Produtos em } \\
\text { Processo }\end{array}$ & 10 & 100 & 0 & 0 & 0 & 0 & 0 & 0 & 10 & 100 \\
\hline Teste de Despesas & 10 & 100 & 0 & 0 & 0 & 0 & 0 & 0 & 10 & 100 \\
\hline $\begin{array}{c}\text { Controle de } \\
\text { Estoques }\end{array}$ & 10 & 21,7 & 6 & 10 & 5 & 8,3 & 36 & 60 & 57 & 100 \\
\hline Controle dos & & & & & & & & & & \\
\hline $\begin{array}{l}\text { Materiais, } \\
\text { Funcionários }\end{array}$ & 9 & 16,1 & 6 & 10,7 & 5 & 8,9 & 36 & 64 & 56 & 100 \\
\hline $\begin{array}{l}\text { Verificar os } \\
\text { maquinários }\end{array}$ & 13 & 21,7 & 6 & 10 & 5 & 8,3 & 36 & 60 & 60 & 100 \\
\hline
\end{tabular}

Fonte: Dados da Pesquisa (2018)

De forma geral, a Tabela 5 expõe que a Auditoria Interna desenvolve $100 \%$ das atividades de testes, com a finalidade de verificar irregularidades nas indústrias, e dando o suporte à Auditoria Externa com $100 \%$ da amostra, também sendo responsável pela maioria das atividades de processos desenvolvidas nas Indústrias. Com isso, observa-se que tudo que está ligado ao processo de fabricação a Auditoria Interna é analisado e verificado.

Neste contexto, enquanto a Controladoria também é responsável pelo controle interno, para alguns respondentes, esta unidade ficaria mais com a parte estratégica, analisando se os procedimentos estão seguidos corretamente, o que 
corrobora com estudos anteriores relacionados à temática (LUNKES; SCHONORRENBERGER, 2009; MOSIMANN; FISCH, 2009; GARCIA, 2010; OLIVEIRA; PEREZ JÚNIOR; SILVA, 2013; PEREZ; SILVA, 2013).

Em complemento, percebe-se também que muitas atividades são desenvolvidas por outras unidades, porém, estas controlam em predominância, os estoques, mão-de-obra, notas fiscais, que são controles necessários para as indústrias analisadas, entretanto, não tendo controles estratégicos e a implantação de novos procedimentos, quando os que estão praticando não atendem as necessidades.

Por fim, quanto ao controle fiscal, a Controladoria desenvolve este processo para $20 \%$ dos respondentes, enquanto outras unidades desenvolvem o processo para $80 \%$ dos respondentes. Em relação à análise e à formação de preço, $62,5 \%$ afirmam que este processo é desenvolvido pela auditoria, enquanto $37,5 \%$ é desenvolvido pela Controladoria, visto que, não há outras unidades desenvolvendo essas atividades.

\section{CONCLUSÃO}

A utilização do controle interno nas empresas tem, dentre outros objetivos, salvaguardar os ativos da empresa, cuja utilização pode ajudar no desenvolvimento das mesmas. Neste aspecto, a presente pesquisa teve como objetivo identificar a responsabilidade do controle Interno nas Indústrias dos municípios de Santa Rita e Bayeux, na Paraíba. Com a finalidade de atender aos objetivos levantados pela pesquisa, realizou-se uma pesquisa bibliográfica sobre o tema abordado e, logo após, a aplicação de questionários em 68 indústrias.

De acordo com os respondentes, a responsabilidade do controle interno é da Auditoria Interna e da gerência da entidade, visto que as duas unidades ficaram equiparadas com a mesma porcentagem, o que diverge com a literatura, que, em tese, atrela à auditoria ou ao Controller os responsáveis pelo processo nas organizações.

No que se refere à responsabilidade, foi constatado que $20,5 \%$ das indústrias não tinham responsáveis pelo controle interno, visto que essa porcentagem é composta por indústrias que não possuíam responsáveis e indústrias em que o responsável era o sócio-proprietário. Quanto à independência na execução das atividades, a maioria dos respondentes afirmou que a Controladoria possui independência; já na execução das atividades, $60 \%$ estão distribuídas em outras unidades ou responsabilidades, quais sejam: Supervisão, Gerência, Direção Administrativa, Contabilidade, Direção de Produção e Proprietário. Em sequência, no que tange às atividades desenvolvidas pelas unidades coletadas na pesquisa foram apontados os Controles Internos, Controle e Acompanhamento Contábil, Auditoria de Processos, Planejamento Estratégico, Custos, Análise e Formação de Preços, Revisão e Controle de Processos, entre outros.

A pesquisa concluiu que a responsabilidade do Controle Interno nos municípios estudados é da Auditoria Interna e da Gerência, e que, apesar de serem abordadas na literatura apenas Auditoria Interna e Controladoria, existem outras unidades que estão desenvolvendo as atividades de Controles Internos nesses municípios. Com base nos resultados, sugere-se que as empresas avaliem os resultados dos trabalhos desses outros profissionais, para verificar se sua 
execução atende as necessidades da empresa, tendo em vista que, a preparação acadêmica para execução dessa atividade, segundo a literatura levantada, seria do controller ou auditor interno.

A principal limitação dessa pesquisa esteve relacionada ao acesso aos respondentes, visto à acessibilidade aos respondentes, endereços e telefones desatualizados. Por fim, recomenda-se estender este trabalho em outros municípios, podendo fazer um comparativo com os resultados dessa pesquisa. 


\title{
Internal Control: Responsibilities and Execution in Industries of Paraiba
}

\begin{abstract}
Internal Control contributes reliable information to decision making in organizations. Therefore, this research aimed to show which unit is responsible for Internal Control in the Industries of the municipalities of Santa Rita and Bayeux, Paraíba. For that, a field survey was carried out, through the application of a questionnaire reaching the quantitative of 68 respondents. According to the data obtained, it was evidenced that the Internal Control responsibility in the analyzed municipalities is, in general, the internal audit and the management. Regarding the independence in the execution of the activities, the majority of the respondents affirmed that the controller has independence. Regarding the activities carried out by the units collected in the research, internal controls, accounting control and monitoring, as well as process auditing, strategic planning and costs were pointed out. Based on the results, it is suggested that companies evaluate the results of the work of these professionals, to verify if their execution meets the needs of the company, considering that the academic preparation to carry out these activities is the Controller or the Internal Auditor.
\end{abstract}

KEYWORDS: Internal Audit. Controllership. Internal control. 


\section{REFERÊNCIAS}

AICPA - AMERICAN INSTITUTE OF CERTIFIED PUBLIC ACCOUNTANTS. 2019. Disponível em: <https://www.aicpa.org/interestareas/frc.html $\geq$. Acesso em: 10 fev. 2019.

ATTIE, W. Auditoria: conceitos e aplicações. 6.ed. São Paulo: Atlas, 2011.

CFC - CONSELHO FEDERAL DE CONTABILIDADE. Resolução n.o 986. Aprova a NBC $\mathrm{TI} 01$ - Da Auditoria Interna. 2003. Disponível em <https://www.ufmg.br/auditoria/images/stories/documentos/nbct12-2003.pdf> Acesso em: 10 fev. 2019.

COSO. Enterprise Risk Management Framework - Executive Summary. 2004. Disponível em: <https://www.coso.org/Documents/COSO-ERM-ExecutiveSummary.pdf $\geq$. Acesso em: 10 fev. 2019.

FRANCO, H. F. E. M. Auditoria Contábil: normas de auditoria; procedimentos e papeis de trabalho; programas de auditoria; relatórios de auditoria. 4. ed. São Paulo: Atlas, 2009.

GARCIA, A. S. Introdução à Controladoria: Instrumentos básicos de controle de gestão das empresas. São Paulo: Atlas, 2010.

GIL, A. C. Métodos e Técnicas de Pesquisa Social. 6. ed. São Paulo: Atlas, 2008.

INSTITUTO BRASILEIRO DE GEOGRAFIA E ESTATISTICA - IBGE. 2018. Disponível em: <https://cidades.ibge.gov.br/brasil/pb/santa-rita/panorama>. Acesso em: 10 FEV. 2019.

KATAOKA, S. S.; CRUZ, V. L.; LIBONATI, J.; MIRANDA, L. C.; NASCIMENTO, S. G. O. de A. S. do. Controladoria $x$ auditoria: um estudo sobre as atividades de controle interno nas empresas de grande porte no estado de Pernambuco. In: Congresso Brasileiro de Custos, 15, 2018. Vitória, ES. Anais...Belo Horizonte, 2018.

LUNKES, R. J.; SCHNORRENBERGER, D. Controladoria na Coordenação dos Sistemas de Gestão. São Paulo: Atlas, 2009.

MARTINS, I.; MORAIS, G. Auditoria Interna, Função e Processo. 4. ed. Áreas Editora, 2013.

MARTINS, P. Análise da Compreensão dos Gestores Municipais quanto à Importância da Auditoria Interna, Controladoria e Controle Interno na Microrregião de Xanxerê SC. 2014. 64 f. Trabalho de Conclusão de Curso (Bacharelado em Ciências Contábeis) - Universidade Tecnológica Federal do Paraná. Pato Branco, 2014.

MOSIMANN, C. P.; FISCH, S. Controladoria: seu papel na administração de empresas. São Paulo: Atlas, 2009.

OLIVEIRA, L. M. de. PEREZ JUNIOR, J. H.; SILVA, C. A. dos. Controladoria Estratégica: textos e casos práticos com solução. 9. ed. São Paulo: Atlas, 2013.

SANTOS, S. R. T. dos. TRES, T. F. Controladoria, Auditoria Interna e Controle Interno: O Entendimento dos Gestores Públicos Municipais Pertencentes ao Corede Produção/RS. In: Congresso USP de Controladoria e Contabilidade, 12, 2012. São Paulo, SP. Anais... São Paulo, 2012. 
SEBRAE. Critérios de classificação de empresas: MEI - ME - EPP. 2016. Disponível em:

<http://www.sebrae.com.br/Sebrae/Portal\%20Sebrae/Anexos/As_pequenas_em presas_SN.pdf>. Acesso em: 10 fev. 2019.

VASCONCELOS, V. L. de; CRUZ, V. L.; SANTOS, R. R. dos; AMORIM, K. A. F. de. As Práticas de Auditoria Interna em uma Cooperativa de Crédito Sob a Perspectiva do coso II. Sociedade, Contabilidade e Gestão, v. 12, n. 2, mai/ago. 2017.

VASCONCELOS, M. C. S.; et al. Modelo para a formatação dos artigos a serem submetidos à Revista Gestão Industrial. R. Gest. Industr., Ponta Grossa, v. 15, n. 1, p. 120-133, jan./mar. 2019. Disponível em: $\leq$ https://periodicos.utfpr.edu.br/rgi $>$. Acesso em: XXX.

Correspondência:

Vera Lúcia Cruz

Universidade Potiguar, Escola de Gestão, Avenida Roberto Freire, 2184, Capim Macio

Natal/RN, Brasil, CEP: 59.082-902

Direito autoral: Este artigo está licenciado sob os termos da Licença Creative Commons-Atribuição 4.0 Internacional.

\section{(c) (1)}

